\title{
Propostas de formação inicial de professores de matemática no estado do Paraná: condicionantes do cenário atual
}

\author{
Márcia Cristina de Costa Trindade Cyrino \\ Professora da Universidade Estadual de Londrina \\ marciacyrino@uel.br
}

\begin{abstract}
Resumo
Neste artigo discutimos algumas propostas de formação inicial de professores de Matemática no Estado do Paraná, considerando os seguintes pontos de enfoque: distribuição e articulação dos componentes curriculares; estágio curricular obrigatório; articulação entre o ensino e a pesquisa; e as impressões de representantes dos cursos a respeito da implantação do projeto pedagógico do curso de licenciatura em Matemática de sua instituição: efeitos, resultados e implicações. Os pontos de enfoque abordados sinalizam um cenário de mudança e de desafios a serem enfrentados quanto à formação inicial de professores de Matemática.
\end{abstract}

Palavras-chave: Educação Matemática; Formação inicial de Professores de Matemática; Licenciatura em Matemática; Propostas Curriculares.

\section{Proposals of pre-service Mathematics Teachers Education in the State of Paraná: conditions of the current setting}

\begin{abstract}
In this paper we discuss some proposals for pre-service mathematics teacher education of undergraduate mathematics courses in the State of Paraná, taking as focus points: components of the curriculum distribution and linkage; student teaching; relationship between teaching and research; and the course coordinators' impressions regarding the development of the pedagogical projects of the undergraduate mathematics courses: effects, results and implications. The focus points indicate a change setting and challenges to be faced regarding pre-service mathematics teacher education.
\end{abstract}

Keywords: Mathematics Education; Pre-service Mathematics Teachers Education; Prospective mathematics teacher education; Curriculum Proposals. 


\section{Introdução}

O número de pesquisas relativas à formação de professores de Matemática tem crescido muito nos últimos anos no Brasil e no mundo, sobretudo, em virtude dos problemas enfrentados nos processos de ensino e de aprendizagem, da complexidade e diversidade da sala de aula, das demandas sociais, dos novos papeis atribuídos ao professor, do currículo e dos conteúdos necessários à formação. No Brasil a formação inicial de professores de Matemática para atuar na educação básica é feita por meio de cursos de licenciatura, que passaram por reformulações significativas após a publicação das "Diretrizes Curriculares para a Formação do Professor da Educação Básica", instituídas por meio das Resoluções CNE/CP nº 01/2002 e 02/2002, e também das "Diretrizes Curriculares Nacionais para os Cursos de Matemática", de acordo com o Parecer CNE/CES 1302/2001.

Nos últimos 10 anos o Grupo de Estudo e Pesquisa sobre Formação de Professores que Ensinam Matemática - GEPEFOPEM tem investigado possíveis fatores intervenientes no processo de constituição de conhecimentos profissionais de professores de Matemática na formação inicial. Desafiados pela temática do VI Fórum Estadual das Licenciaturas em Matemática do Paraná (VI FELIMAT-PR) denominada "A implantação dos Projetos Políticos dos Cursos de Licenciatura em Matemática no Paraná: efeitos, resultados e implicações”, o GEPEFOPEM realizou em 2012 um levantamento de informações junto aos representantes dos cursos de licenciatura em Matemática do Paraná com o objetivo de obter elementos que pudessem fomentar as discussões desse fórum.

Nesse artigo discutimos algumas propostas de formação inicial de professores de Matemática no Paraná, na tentativa de compreender alguns condicionantes do cenário atual. Para sacudir as "teias de aranha" nas "poeirentas prateleiras da memória coletiva", apresentamos inicialmente documentos e ações que orientaram (re)elaborações dos Projetos Pedagógicos (PP) de cursos de licenciatura em Matemática no Brasil e no Paraná.

\section{A formação inicial de professores de Matemática: caminhos e descaminhos}

Os primeiros cursos de licenciatura em Matemática no Brasil foram criados nas Faculdades de Filosofia, Ciências e Letras - FFCL. A primeira delas foi a Faculdade de Filosofia, Ciências e Letras, da Universidade de São Paulo, a partir de 1934, formando exclusivamente matemáticos e professores de Matemática para o ensino superior e para o ensino secundário. O modelo de formação assumido ficou conhecido popularmente como " $3+1$ ”, ou seja, a partir da formação de bacharéis acrescentava-se um ano com disciplinas da área de educação para a obtenção da licenciatura. 
Após a Primeira e a Segunda Guerras Mundiais ocorreu no Brasil uma queda generalizada do prestígio dos docentes e a instauração de um ambiente de incredulidade com relação ao ideal escolar. No período conhecido como "nacional-desenvolvimentista", cresceu a necessidade de mão-de-obra especializada e semiespecializada, e o Estado, visando manter o apoio ao quadro político de desenvolvimento econômico e conter o processo de mobilização social, promoveu a expansão da escola, o que fez com que se mudasse a composição social dos interessados nos cursos de formação de professores. Com o aumento no número de alunos e de escolas ocorreu um substancial incremento na demanda de professores de Matemática e, por conseguinte, uma expansão desordenada dos cursos de formação que contribuiu para a proletarização do professor, o seu distanciamento da produção do saber, a dificuldade de trabalhar com a diversidade, dentre outros aspectos.

Com a publicação da Lei de Diretrizes e Bases da Educação Nacional - Lei n ${ }^{\circ}$ 9.294/96 e com o avanço das pesquisas a respeito da formação de professores adentramos o século XXI com novas propostas às instituições responsáveis pela formação de professores, o que culminou com a publicação, em 2002, das Diretrizes Curriculares Nacionais para a Formação de Professores (Resoluções CNE/CP01 e CP02).

A Sociedade Brasileira de Educação Matemática - SBEM procurou participar ativamente das discussões para elaboração das Diretrizes Curriculares Nacionais dos Cursos de Matemática (Licenciatura e Bacharelado). O Conselho Nacional Deliberativo - CND da SBEM propôs, em 2002, a realização de fóruns estaduais, com o objetivo de desencadear discussões na tentativa de produzir propostas, entre a comunidade de educadores matemáticos, que pudessem contribuir para elaboração dos PP.

No Paraná, a Diretoria Regional da SBEM-PR e o Departamento de Matemática da UEL, com a colaboração do Conselho Estadual de Educação - CEE-PR, e apoio da Fundação Araucária, promoveram em junho de 2002 o I FELIMAT-PR, para o qual foram convidados representantes de todas as Instituições de Ensino Superior (IES) que mantinham curso de licenciatura em Matemática no estado. As indicações elaboradas nesse evento foram apresentadas e discutidas no I Fórum Nacional de Licenciatura em Matemática realizado, em agosto de 2002, na PUC-SP. Este fórum tinha a finalidade de socializar os resultados dos fóruns regionais e elaborar uma proposta da SBEM para os cursos de licenciatura em Matemática a ser encaminhada ao Conselho Nacional de Educação - CNE como subsídio para elaboração das diretrizes. No entanto, os participantes foram surpreendidos com a notícia de que o Ministro de Estado da Educação já havia homologado, em 04/03/2002, o Parecer no 1302/2001, da Câmara de Educação Superior do CNE, aprovando as "Diretrizes Curriculares Nacionais dos Cursos de Matemática". Diante disso, os participantes decidiram encaminhar ao CNE um documento apontando inconsistências dessas dire- 
trizes com as pesquisas da área e solicitando abertura de espaços para a participação das IES e das sociedades científicas na (re)elaboração das diretrizes. Infelizmente, a solicitação não foi atendida.

Em 2003, a SBEM promoveu o I Seminário Nacional para a discussão dos Cursos de Licenciatura em Matemática, em Salvador/Bahia, com o propósito de analisar e discutir o conteúdo de um documento-síntese que continha as propostas elaboradas pelas Diretorias Regionais da SBEM, apresentar resultados de pesquisas nacionais e produzir orientações que favorecessem a elaboração dos PP dos cursos, sistematizadas no documento intitulado "Subsídios para a discussão de propostas para os cursos de licenciatura em matemática: uma contribuição da Sociedade Brasileira de Educação Matemática" ${ }^{1}$. Esse documento listou também vários problemas a serem enfrentados pelos cursos de licenciatura em Matemática, muitos dos quais, comuns a outras licenciaturas e lembrados no corpo da Resolução CNE/CP1 (2002).

Transcorridos quase dois anos do prazo máximo estipulado para a adequação dos cursos à legislação em vigor, em 2007, a SBEM - Regional Paraná organizou o II FELIMAT-PR, em Assis Chateaubriand, com o objetivo de dar continuidade às discussões a respeito dos "caminhos tomados" pelos cursos, desvelando avanços e desafios a serem enfrentados no estado. Os resultados desse evento foram apresentados no II Fórum Nacional, realizado no final do mesmo ano. Nesse evento, os participantes discutiram a existência de indicativos de alterações das atuais diretrizes para formação de professores para a Educação Básica por meio do Parecer CNE/CP $n^{\circ}$ 5/2006 e do Projeto de Resolução anexo ao Parecer CNE/CP n ${ }^{\circ}$ 9/2007.

A partir de 2007 as discussões no Paraná se intensificaram com a organização quase que periódica de fóruns, com o objetivo de avaliar o processo de implantação dos PP dos cursos de licenciatura em Matemática nas IES do estado e debater possibilidades de ações coletivas, voltadas para superação de dificuldades decorrentes dessa implantação. Assim, foram realizados os seguintes eventos:

- III FELIMAT, em 2008 na Universidade Estadual do Oeste do Paraná UNIOESTE campus de Foz do Iguaçu.

- IV FELIMAT ${ }^{2}$, em 2009 na Universidade Estadual do Centro-Oeste do Paraná - UNICENTRO em Guarapuava.

- V FELIMAT ${ }^{3}$, em 2011 na Universidade Estadual de Ponta Grossa - UEPG.

- VI FELIMAT4, em 2012 na Universidade Estadual do Oeste do Paraná UNIOESTE campus de Cascavel.

1. http://www.prg.rei.unicamp.br/ccg/subformacaoprofessores/SBEM_licenciatura.pdf

2. http://www.unicentro.br/eprem2009/felimat.asp

3. $\mathrm{http}: / /$ sbemdf.com/index.php?option $=$ com_ckforms\&view $=$ ckforms $\&$ id $=5 \&$ Itemid $=40$

4. http://www.cascavel.unioeste.br/index.php?option=com_content\&view $=$ article\&id=882\&Itemid $=1542$ 
- VII FELIMAT, em 2013 na Universidade Tecnológica Federal do Paraná UTFPR campus Toledo.

Vale destacar que os participantes dos FELIMAT têm se esforçado em manter vivo o debate a respeito da formação inicial de professores de Matemática, considerando suas experiências e pesquisas na área.

\section{Contexto investigado e encaminhamento metodológico}

A diminuição da procura, concomitantemente ao aumento da oferta, por cursos de licenciatura em Matemática é um dos paradoxos que vêm sendo observados nos últimos anos no estado do Paraná. Em um mapeamento realizado em 2008, Moriel-Junior (2009) constatou a existência de 31 cursos presenciais de licenciaturas em Matemática no Paraná. Em abril de 2012, o GEPEFOPEM ${ }^{5}$ realizou um levantamento, a partir da base de dados do Ministério da Educação e Cultura - MEC/INEP ${ }^{6}$ e constatou a existência de 44 cursos de licenciatura em Matemática no Paraná, 33 presenciais e oferecidos por 29 IES (Tabela 1).

\section{Tabela 1}

Distribuição dos cursos de licenciatura em Matemática no Paraná7

\begin{tabular}{|c|c|c|c|c|}
\hline \multirow{3}{*}{$\begin{array}{l}\text { Instituições de Ensino Superior } \\
\text { (categoria administrativa) }\end{array}$} & \multicolumn{3}{|c|}{ Cursos de licenciatura em Matemática } & \multirow{3}{*}{ Total } \\
\hline & \multirow[b]{2}{*}{ Presencial } & \multicolumn{2}{|c|}{ À Distância (EAD) } & \\
\hline & & $\begin{array}{l}\text { Sediadas } \\
\text { no PR }\end{array}$ & $\begin{array}{l}\text { Não } \\
\text { sediadas no } \\
\text { PR }\end{array}$ & \\
\hline Instituições Públicas & 19 & 1 & 1 & 21 \\
\hline Instituições Privadas & 14 & 0 & 9 & 23 \\
\hline Total & 33 & 1 & 10 & 44 \\
\hline
\end{tabular}

Fonte: MEC/INEP

Na busca de informações que nos permitissem investigar propostas de formação inicial de professores de Matemática no Paraná, enviamos aos representantes dos cursos de licenciatura em Matemática presenciais e do curso à distância sediado no Paraná, um questionário eletrônico cujas respostas ficaram armazenadas em uma base

5. Agradecemos aos membros do GEPEFOPEM que colaboraram com a elaboração do instrumento de coleta de informações e com a primeira organização dos dados dessa pesquisa.

6. http://www.educacaosuperior.inep.gov.br

7. As instituições UENP, UNIPAR, UNIOESTE, UNICENTRO e UTFPR oferecem mais do que um curso, por serem multicampi. 
de dados, com a possibilidade de anexar documentos. Esse questionário solicitava informações de cunho geral, tais como: tempo mínimo de integralização, modalidade (presencial, a distância, semi-presencial), turno, etc, bem como informações específicas a respeito de sua proposta pedagógica, nomeadamente quanto: a matriz curricular do curso; ao estágio curricular obrigatório; as práticas como componente curricular (se há articulação com o estágio curricular supervisionado); ao modo como as 200 horas de atividades acadêmico-científico-culturais estão distribuídas, quais as atividades previstas e como foram regulamentadas na IES; ao modo como a pesquisa está inserida no PP; aos egressos; ao uso de tecnologias; as impressões do Colegiado a respeito da implantação do PP de sua instituição: efeitos, resultados e implicações.

Obtivemos o retorno de representantes de 15 cursos (44\%), que para o propósito deste artigo serão denominados por $\mathrm{C} 1, \mathrm{C} 2, \ldots, \mathrm{C} 15$ (Curso 15), no intuito de preservar a identidade desses cursos. Dentre os que responderam ao questionário, 14 cursos têm oferta presencial e um a distância. Quanto a categoria administrativa, 11 cursos (73\%) são de instituições públicas e os outros quatro (27\%) de instituições particulares. Em apenas um desses cursos o tempo mínimo para integralização é de três anos, ao passo que nos demais o prazo mínimo é de quatro anos. O turno de oferta está distribuído da seguinte forma: em uma instituição o curso é ofertado nos períodos matutino e noturno, em outra no período matutino, uma com oferta integral (EAD), e em 12 IES o curso é ofertado somente no período noturno.

As respostas foram analisadas em conjunto com os documentos enviados (PP do Curso, Regulamento de Estágio, etc.) utilizando Análise de Conteúdo (BARDIN, 1977). Procuramos obter, a partir de procedimentos sistemáticos e objetivos de descrição do conteúdo das respostas e dos documentos, indicadores que nos permitissem fazer inferências a respeito do que foi perguntado. Inicialmente fizemos uma pré-análise das informações de modo a escolher o material que seria utilizado na análise, para em seguida explorarmos o material e tratarmos as respostas e partes dos documentos que forneceram indicadores necessários à interpretação e a inferência.

\section{Propostas de formação inicial de professores de Matemática no estado do Paraná}

Decorridos mais de 10 anos de debates, desencadeados pela publicação das diretrizes, apresentamos a seguir alguns condicionantes do cenário atual de cursos de licenciatura em Matemática no Estado do Paraná, considerando os seguintes pontos de enfoque: distribuição e articulação dos componentes curriculares; estágio curricular obrigatório; articulação entre o ensino e a pesquisa; e as impressões de representantes dos cursos a respeito da implantação do PP do curso de licenciatura em Matemática de sua instituição: efeitos, resultados e implicações. 


\section{Distribuição e articulação dos componentes curriculares}

Ao analisar a distribuição de carga horária dos componentes curriculares obrigatórios observamos que a maioria dos cursos atende à legislação vigente. As cargas horárias totais dos cursos variam de 2825 h a 3502 h entre disciplinas formadoras, estágio curricular supervisionado, atividade acadêmica complementar e prática como componente curricular. A partir da análise das ementas das disciplinas formadoras, realizamos o seguinte agrupamento:

- Disciplinas de Conteúdos Matemáticos ${ }^{8}$;

- Disciplinas de Educação Matemática ${ }^{9}$;

- Disciplinas de Conhecimentos Gerais de Educação ${ }^{10}$;

- Outros conhecimentos ${ }^{11}$.

Na Tabela 2 sintetizamos a carga horária média dos grupos de disciplinas. Considerando o conjunto das instituições, a carga horária destinada às disciplinas de Conteúdo Matemático (56,5\%), exceto em uma IES, é superior a 50\%, sendo que em um terço dos cursos essa carga horária é igual ou superior a $60 \%$. O grupo de "Análise" assume 24,4\% da carga horária total do curso. Vale ressaltar que 23,7\% das disciplinas ofertadas referem-se às áreas de "Educação Matemática" e "Conhecimentos Gerais de Educação" juntas. Adicionalmente, as disciplinas que envolvem, de algum modo, conhecimentos de "como ensinar" como, por exemplo, "Didática e Psicologia da Matemática", "Prática e Metodologia do Ensino de Matemática" e "Tendências da Educação Matemática" apresentam ementas bastante heterogêneas e representam apenas $12,1 \%$ da carga horária total.

8. Nesse grupo consideramos as disciplinas de Matemática Básica (Fundamentos de Matemática, Elementos de Matemática, Lógica, dentre outras), Geometria e Desenho (Geometria Analítica, Geometria Euclidiana, Introdução a Geometria, Geometria não-euclidiana, Geometria Descritiva, Desenho Geométrico, dentre outras), Álgebra (Álgebra Linear, Estruturas Algébricas, Álgebra Moderna, dentre outras), Análise (Cálculo, Análise Real, Cálculo Numérico, Equações Diferenciais, dentre outras), e Matemática Aplicada (Algoritmos de Programação, Matemática Computacional, Métodos Numéricos, Pesquisa Operacional, dentre outras).

9. Nesse grupo foram contabilizadas as disciplinas relacionadas às Tendências da Educação Matemática, Didática e Psicologia da Matemática (Didática da Matemática e Psicologia da Matemática), História e Filosofia da Matemática (História da Matemática, Filosofia da Matemática, Filosofia da Educação Matemática), Prática e Metodologia do Ensino de Matemática (Prática de Ensino de Matemática, Metodologia do Ensino de Matemática, Laboratório de Ensino de Matemática), Modelagem Matemática na perspectiva da Educação Matemática, enfim àquelas que envolvem aspectos dos processos de ensino e de aprendizagem de Matemática.

10. Consideramos as disciplinas que envolvem Didática (Didática Geral), Psicologia da Educação, Sociologia e Filosofia da Educação, Fundamentos da Educação, Políticas Educacionais (Políticas Públicas da Educação, Gestão Educacional, Legislação Educacional, Cidadania e Sociedade, História e Cultura dos povos Indígenas e afro-brasileiros, Educação de Jovens e Adultos, dentre outras).

11. Nesse grupo foram contabilizadas disciplinas eletivas, Matemática Financeira, Física, Probabilidade e Estatística, Informática, Libras, Iniciação a Pesquisa, Trabalho de Conclusão de Curso, dentre outras. 


\section{Tabela 2}

Carga horária dos grupos de disciplinas dos cursos de licenciatura em Matemática

\begin{tabular}{|c|c|c|c|c|c|}
\hline \multirow{2}{*}{\multicolumn{2}{|c|}{ Grupo de disciplinas }} & \multicolumn{4}{|c|}{ Carga Horária Média } \\
\hline & & \multirow{2}{*}{$\begin{array}{r}\begin{array}{r}\text { TEÓRICA } \\
\text { (horas) }\end{array} \\
167,9\end{array}$} & \multirow{2}{*}{$\begin{array}{r}\begin{array}{r}\text { PRÁTICA } \\
\text { (horas) }\end{array} \\
24,2\end{array}$} & \multirow{2}{*}{$\begin{array}{r}\text { TOTAL } \\
\text { (horas) }\end{array}$} & \multirow{2}{*}{$\frac{\%}{7,6}$} \\
\hline \multirow{6}{*}{$\begin{array}{l}\text { Conteúdos } \\
\text { Matemáticos }\end{array}$} & Matemática Básica & & & & \\
\hline & Geometria e Desenho & 288,3 & 38,7 & 327,0 & 12,9 \\
\hline & Álgebra & 239,2 & 10,0 & 249,2 & 9,9 \\
\hline & Análise & 575,9 & 40,9 & 616,8 & 24,4 \\
\hline & Matemática Aplicada & 28,2 & 13,9 & 42,1 & 1,7 \\
\hline & $\begin{array}{l}\text { Subtotal (soma } \\
\text { da carga horária } \\
\text { média) }\end{array}$ & 1299,5 & 127,7 & 1427,2 & 56,5 \\
\hline \multirow{6}{*}{$\begin{array}{l}\text { Educação } \\
\text { Matemática }\end{array}$} & $\begin{array}{l}\text { Tendências da } \\
\text { Educação Matemática }\end{array}$ & 13,9 & 20,1 & 34 & 1,4 \\
\hline & $\begin{array}{l}\text { Didática e Psicologia } \\
\text { da Educação } \\
\text { Matemática }\end{array}$ & 26,6 & 22,5 & 49,1 & 1,9 \\
\hline & $\begin{array}{l}\text { História e Filosofia da } \\
\text { Matemática }\end{array}$ & 65,2 & 11,2 & 76,4 & 3,0 \\
\hline & $\begin{array}{l}\text { Prática e Metodologia } \\
\text { do Ensino de } \\
\text { Matemática }\end{array}$ & 93,5 & 128,0 & 221,5 & 8,8 \\
\hline & $\begin{array}{l}\text { Modelagem } \\
\text { Matemática na } \\
\text { perspectiva da } \\
\text { Educação Matemática }\end{array}$ & 21,6 & 11,7 & 33,3 & 1,3 \\
\hline & $\begin{array}{l}\text { Subtotal (soma } \\
\text { da carga horária } \\
\text { média) }\end{array}$ & 220,8 & 193,5 & 414,3 & 16,4 \\
\hline \multirow{6}{*}{$\begin{array}{l}\text { Conhecimentos } \\
\text { Gerais de } \\
\text { Educação }\end{array}$} & Didática & 27,2 & 9,9 & 37,1 & 1,5 \\
\hline & $\begin{array}{l}\text { Psicologia da } \\
\text { Educação }\end{array}$ & 47,3 & 3,1 & 50,4 & 2,0 \\
\hline & $\begin{array}{l}\text { Sociologia e Filosofia } \\
\text { da Educação }\end{array}$ & 15,5 & 0,1 & 15,6 & 0,6 \\
\hline & $\begin{array}{l}\text { Fundamentos da } \\
\text { Educação }\end{array}$ & 22,8 & 0,1 & 22,9 & 0,9 \\
\hline & $\begin{array}{l}\text { Políticas } \\
\text { Educacionais }\end{array}$ & 53,4 & 4,5 & 57,9 & 2,3 \\
\hline & $\begin{array}{l}\text { Subtotal (soma } \\
\text { da carga horária } \\
\text { média) }\end{array}$ & 166,2 & 17,7 & 183,9 & 7,3 \\
\hline \multicolumn{2}{|c|}{ Outros conhecimentos } & 415,7 & 84,2 & 499,9 & 19,8 \\
\hline \multicolumn{2}{|l|}{ Total } & 2102,2 & 423,1 & 2525,3 & 100,0 \\
\hline
\end{tabular}

Fonte: Projetos Pedagógicos dos cursos 
As disciplinas que envolvem conhecimentos de "Fundamentos da Educação" e "Políticas Educacionais" registram percentuais inexpressivos. Esses percentuais sugerem que os cursos fornecem pouca informação e reflexão a respeito do contexto educacional e das políticas públicas vigentes, fato que pode justificar o "choque de realidade" vivenciado por alguns licenciandos no desenvolvimento do estágio supervisionado (CYRINO; PASSERINI, 2009). Além disso, há um grande número de disciplinas elencadas em "outros conhecimentos" (19,8\%), que pode representar uma adequação as necessidades locais de cada curso, ou uma pulverização na formação do licenciando que revela fragilidade na preparação para o exercício da profissão.

Observamos, ainda, outras dissonâncias na distribuição da carga horária relativas:

- às disciplinas de "Conhecimentos Gerais de Educação". Há cursos que apresentam uma carga horária irrisória, ou ausente, e outros com uma carga horária superior a $10 \%$ da carga total do curso.

- à distribuição das $400 \mathrm{~h}$ destinadas as Prática como Componente Curricular - PCC. Por exemplo, quatro cursos não apresentam a PCC no grupo de disciplinas de "Conteúdo Matemático", enquanto em sete cursos elas não são contempladas nas disciplinas de "Conhecimentos Gerais de Educação".

Vale destacar que as Diretrizes Curriculares Nacionais para Formação de Professores (2002) sugerem articulação entre conhecimentos específicos de formação e àqueles que farão parte da realidade profissional do professor, por meio da PCC. Assim, de acordo com o artigo 12 deste documento:

$\S 1^{\circ}$ a prática, na matriz curricular, não poderá ficar reduzida a um espaço isolado, que a restrinja ao estágio, desarticulado do restante do curso; $\S 2^{\circ}$ a prática deverá estar presente desde o início do curso e permear toda a formação do professor; $\S 3^{\circ}$ no interior das áreas ou das disciplinas que constituírem os componentes curriculares de formação, e não apenas nas disciplinas pedagógicas, todas terão a sua dimensão prática (p.5-6).

Os cursos de licenciatura em Matemática precisam ser pautados em uma formação holística que atinge tanto a teoria quanto a prática como dimensões do conhecimento, articulando-as em torno dos diferentes eixos que compõem a matriz curricular (grupos de disciplinas). Nesta perspectiva, a relação teoria e prática deve permear todo o desenvolvimento profissional do professor de Matemática, possibilitando a (re)elaboração de aprendizagens da docência no decorrer do processo formativo. 
Na maioria dos PP a formação de professores para atuarem na Educação Básica é destacada como objetivo ou meta. No entanto, os conteúdos de Matemática abordados no decorrer do curso pouco se relacionam com a matemática escolar. As ementas das disciplinas de formação específica têm uma abordagem predominantemente descritiva e, apesar da carga horária estar subdividida em "Teoria" e "Prática", não foi possível perceber o que se entende por "prática”, tão pouco se há articulação entre teoria e prática e como ela se efetiva. É preciso considerar que, uma simples análise das ementas pode não revelar articulação entre teoria e prática, entre matemática acadêmica e matemática escolar, no entanto o que nos preocupa é a ausência de discussão, em alguns PP, de como podem ser promovidas tais articulações. Da forma como está descrito, essa função fica a cargo de cada professor formador. Até mesmo as disciplinas que, pela sua natureza, estariam mais relacionadas aos conteúdos matemáticos a serem ministrados na Educação Básica têm uma predominância de aspectos teóricos que fundamentam teorias de ensino, em detrimento das práticas educacionais associadas a esses aspectos.

Além dos dados presentes nos PP, alguns representantes dos cursos revelaram que, de modo geral, as "práticas" concentram-se nas disciplinas da área de Educação Matemática (45,7\% da carga horária total destinada à prática). Nos PP que revelam indícios de articulação entre teoria e prática, esses estão associados à pesquisa empírica do futuro professor envolvendo a sala de aula, ao trabalho de pesquisa de final de curso, ao tratamento da matemática escolar em disciplinas específicas e à reflexão didático-pedagógica no contexto de disciplinas que discutem o ensino de Matemática ${ }^{12}$.

De acordo com as Diretrizes (2006) as "Atividades Acadêmicas Complementares" devem "propiciar (ao futuro professor) uma complementação de sua postura de estudioso e pesquisador". Nos cursos investigados são consideradas a participação em: monitorias acadêmicas (em 60\% dos cursos); projetos de ensino, de pesquisa e de extensão (em 86,7 \% dos cursos); eventos científicos (em 100\% dos cursos); estágio voluntário (em 46,7\% dos cursos), cursos de extensão (em 46,7\% dos cursos); disciplinas especiais ou eletivas (em $40 \%$ dos cursos); entre outras.

Em todos os cursos investigados há pelo menos uma disciplina em sua matriz curricular que trata do uso de tecnologias. O nome das disciplinas varia muito, o rótulo mais utilizado é "Informática aplicada à Educação", com uma carga horária média de $72 \mathrm{~h}$. Seis representantes de cursos declararam que além de possuírem uma disciplina específica para discutir esse assunto, professores de outras disciplinas

12. Em Moriel-Junior e Cyrino (2009) pode ser encontrado um conjunto de propostas que pode favorecer a articulação teoria e prática e fortalecer nexos entre a profissão docente e a formação inicial de professores de Matemática. 
fazem uso da tecnologia ou discutem a sua importância ou utilização na educação em seus programas disciplinares.

\section{Estágio Curricular Obrigatório}

O estágio curricular obrigatório é um espaço privilegiado para a aprendizagem de práticas docentes e tem, por princípio, que proporcionar aos licenciando uma imersão no seu futuro campo de atuação profissional. As instituições investigadas garantem o número mínimo de horas de estágio previstas na legislação. Tivemos acesso ao Regimento de Estágio de 12 IES. A maioria desses regimentos contempla: princípios e diretrizes legais, os objetivos do estágio, a distribuição da carga horária, as atividades a serem desenvolvidas, aspectos relacionados à orientação e à supervisão do estágio, às atribuições do coordenador, do estagiário e do colegiado do curso, à avaliação do estágio e às normas de elaboração do relatório.

A carga horária de estágio está distribuída entre Ensino Fundamental e Ensino Médio. No regimento de dois cursos não há uma descrição de quais atividades devem ser desenvolvidas no estágio e como devem ocorrer, indicam apenas onde (campo de estágio). As atividades contemplam: estágio de observação, estágio de coparticipação ou participação, elaboração dos planos de aula e de materiais didáticos para o estágio de regência, estágio de regência, e elaboração do relatório de estágio.

Os cursos que apresentam em seu regimento de Estágio a "coparticipação" como uma das atividades de Estágio, não deixam claro ao que se referem. Em um deles está descrito que "compreende-se por coparticipação, atividades relacionadas à prática docente em sala de aula", entretanto, não explicita quais ações devem ser realizadas pelo estagiário, indicam somente que essas serão desenvolvidas em parceria com o professor da escola (campo de estágio). Vale destacar que alguns cursos têm assumido formas alternativas para a realização dos estágios de regência, para além das aulas regulares, tais como: minicursos e oficinas a respeito de conteúdos matemáticos específicos, em horários ou dias alternativos, como por exemplo, aos sábados.

As orientações, de acordo com os regimentos, estão sob a responsabilidade de docentes das IES (professor-formador). No entanto, a supervisão pode ser compartilhada com os professores das escolas. Um dos regimentos analisados descreve quais devem ser as atribuições do professor da escola (denominado como professor regente), não em forma de obrigações, já que esta é de responsabilidade do professor-formador, mas apresentando exemplos de ações pelas quais o professor da escola pode assumir o papel de formador de professores. 
O Professor Regente é aquele que ministra aula regularmente nas turmas nas quais os estagiários realizarão o Estágio Curricular Supervisionado. A ele não é delegada nenhuma obrigação no que se refere ao Estágio, responsabilidade única da Instituição Formadora. Contudo, ele pode contribuir da seguinte forma:

I. ceder suas aulas para que o acadêmico possa realizar suas atividades de estágio;

II. informar sobre o seu planejamento de atividades de modo a permitir que o acadêmico estagiário dê continuidade ao seu trabalho;

III. acompanhar as atividades do acadêmico durante as aulas para assegurar a continuidade da formação dos seus alunos, bem como resguardar os interesses e a integridade do funcionamento da escola;

IV. registrar e encaminhar ao professor da disciplina de Metodologia do Ensino de Matemática aspectos teóricos e/ou pedagógicos que possam contribuir com a avaliação do acadêmico estagiário;

V. solicitar, com anuência da Direção da Escola, o desligamento do estagiário que não apresentar condições mínimas de regência das aulas ou desrespeitar as normas do convênio de estágio, deste regulamento ou da escola concedente. (PP do C9, p. 14).

Na maioria dos cursos, de acordo com seus representantes, a atuação do professor da escola está restrita a definição dos temas a serem trabalhados, e em alguns casos ele tem participação no planejamento das tarefas a serem desenvolvidas (C2, C7, C10, C12) e na avaliação dos estagiários (C2, C7, C9, C10, C12, C14). Essa avaliação envolve análise do plano de atividades $(\mathrm{C} 2)$; da regência, por meio da supervisão do estágio (C9, C10, C12, C14); e de todo o processo (C7).

Consideramos importante o desenvolvimento de um trabalho colaborativo entre o professor-formador, o estagiário e o professor da escola. Não basta informar ao professor da escola o que deve ou não ser feito. É preciso constituir grupos de estudo e discussão nos quais seus membros assumam o compromisso com a sua formação e com a formação do outro, compartilhem repertórios, articulem empreendimentos comuns, baseados em uma relação de confiança, sem constrangimentos, na busca de conhecimentos e de uma autonomia pedagógica responsável (comprometida com o aprendizado do aluno, do futuro professor, do professor e do professor-formador).

As orientações relativas ao Relatório de Estágio são normativas. Em nenhum regimento de estágio e PP dos cursos há indicação da exploração das potencialidades formativas desse tipo de comunicação escrita para a formação inicial de professores de Matemática (TEIXEIRA; CYRINO, 2010, 2011; CYRINO; TEIXEIRA, 2011). 


\section{Articulação entre o ensino e a pesquisa}

Doze representantes de curso forneceram informações a respeito do modo como a pesquisa é contemplada na formação inicial de professores. Em oito cursos a pesquisa está vinculada à participação do futuro professor em grupos e projetos de pesquisa de docentes, por meio do Programa de Iniciação Científica (IC), do Trabalho de Conclusão de Curso (TCC) ou do Estágio Supervisionado (assumido como campo de pesquisa da própria prática). Na maioria das IES a pesquisa não é uma ação obrigatória, embora seja considerada na carga horária do estudante como Atividade Acadêmica Complementar. Para os demais cursos não foi possível verificar qualquer participação dos futuros professores em atividades de pesquisa.

A pesquisa na formação inicial de professores pode ser um ponto de partida para reflexão a respeito da complexidade que envolve o trabalho docente, de questões que surgem na sala de aula relacionadas aos conteúdos, à metodologias, ao comportamento, ao desenvolvimento cognitivo, entre outras; para aproximação entre os aspectos teóricos e práticos da formação do professor de Matemática e de sua futura atuação profissional ${ }^{13}$.

\section{Impressões dos representantes de cursos a respeito da implementação dos}

\section{Projetos Pedagógicos}

Os PP são considerados como base legal para o funcionamento dos cursos. Os representantes dos cursos investigados tiveram dificuldades em expressar as suas impressões, ou as impressões do colegiado do curso a respeito dos efeitos, resultados e implicações da implantação dos PP vigentes fornecendo, por vezes, respostas evasivas. Os argumentos utilizados indicam que a implementação do PP permitiu direcionar as atividades e as regulamentações, dando respaldo e credibilidade às ações dos professores formadores; oportunizar aos futuros professores uma vivência na escola e na sala de aula antes da realização do estágio, por meio das práticas enquanto componente curricular; desenvolver ações mais coerentes para com a instituição, a sociedade e os futuros professores; discutir com os licenciandos, desde o $1^{\circ}$ ano do curso, o que é ser um professor de Matemática; articular os conteúdos matemáticos com as práticas pedagógicas, propiciando um maior comprometimento do docente com a disciplina e o direcionamento de ações metodológicas mais dinâmicas; articular as ementas, por meio de uma construção coletiva da grade curricular pelos professores do curso, que desencadeou interação entre os docentes e uma visão interdisciplinar do curso; e atender à demanda docente da região.

13. Nos anais do VI FELIMAT estão descritas algumas ideias para a elaboração de uma proposta de operacionalização da pesquisa nos cursos de licenciatura em Matemática, permeando todo o processo de formação. 


\section{Concluindo}

É imperativo que as (re)estruturações de propostas de formação inicial de professores de Matemática sejam orientadas por pesquisas e por uma ampla avaliação decorrente de debates entre educadores matemáticos envolvidos com esta etapa de formação e com a Educação Básica. O nosso estudo, apesar de não contemplar informações de todos os cursos de licenciatura em Matemática do estado do Paraná, buscou desvelar alguns condicionantes do cenário atual, assumindo os resultados como um conjunto de "efeitos cênicos" de algumas licenciaturas.

Os resultados de nossa pesquisa sinalizam: indícios de implementação de "práticas" nas disciplinas de conteúdo matemático, apesar dessas estarem concentradas nas disciplinas da área de Educação Matemática; que parte da carga horária de alguns cursos foi atribuída às disciplinas que atendem aspectos específicos da Educação Matemática, antes destinada a conhecimentos gerais da educação ou da matemática que, muitas vezes, guardavam certa distância da futura prática profissional do professor de Matemática; a presença das tecnologias aplicadas à educação; uma maior aproximação do futuro professor com o seu futuro campo de atuação profissional; a busca de um trabalho articulado entre professor formador e professor da escola, no desenvolvimento do estágio curricular supervisionado; e a presença da pesquisa na formação inicial.

No entanto, os dados não indicam mudanças substanciais quanto ao modelo de formação inicial de professores de Matemática já consagrado no século passado. Ainda é muito marcante a tradição disciplinar, como "o feitor na mente do escravo". Não foi possível observar a presença de um programa de formação que privilegie tempos e espaços curriculares diferenciados nos quais o futuro professor de Matemática possa vincular o contexto histórico no qual se dá a sua formação com a necessidade de reconstruir constantemente as condições de trabalho escolar face às mudanças da sociedade, (trans)formando-se em um agente de mudanças capaz de desnormatizar as formas de conhecimento vigentes e pensar em formas alternativas de ensino impulsionadas e motivadas pela reflexão e pelo respeito à diversidade.

Consideramos importante manter o debate e a disposição para o enfrentamento dos desafios impostos à formação inicial de professores, para que possamos fomentar novas pesquisas e políticas públicas de formação inicial que orientem programas alternativos de formação que promovam a constituição da identidade profissional dos futuros professores de Matemática.

Agradecimentos: À Fundação Araucária e ao Conselho Nacional de Desenvolvimento Científico e Tecnológico (CNPq). 


\section{Referências}

BARDIN, L. Análise de conteúdo. Lisboa: Edições 70 Ltda., 1977.

BRASIL. Resolução CNE/CP n. ${ }^{\mathbf{1}}$ 1, de 18 de fevereiro de 2002. Institui Diretrizes Curriculares Nacionais para a Formação de Professores da Educação Básica, em nível superior, curso de licenciatura, de graduação plena. Brasília, DF, 2002.

CYRINO, M. C. C. T.; PASSERINI, G. A. Reflexões sobre o estágio supervisionado do curso de licenciatura em Matemática da Universidade Estadual de Londrina. In: CAINELLI; M.; FIORELI, I. (Org.). O estágio na licenciatura: a formação de professores e a experiência interdisciplinar na Universidade Estadual de Londrina. Londrina: UEL/Prodocencia, 2009. p. 125-144.

CYRINO, M. C. C. T. ; TEIXEIRA, B. R. O Estágio Supervisionado e o Relatório de Estágio como espaços de reflexão sobre a Resolução de Problemas. Perspectivas da Educação Matemática, Campo Grande, v. 4, n. 1, p. 136-156, 2011.

MORIEL-JUNIOR, J. G.; CYRINO, M. C. C. T. Propostas de articulação entre teoria e prática em cursos de licenciatura em Matemática. Educação Matemática Pesquisa, São Paulo, v.11, n.3, p.535-557, 2009.

\section{SOCIEDADE BRASILEIRA DE EDUCAÇÃO MATEMÁTICA - SBEM. Subsídios} para a discussão de propostas para os cursos de Licenciatura em Matemática: uma contribuição da Sociedade Brasileira de Educação Matemática. São Paulo, 2003. Disponível em: $<$ http://www.prg.rei.unicamp.br/ccg/subformacaoprofessores/ SBEM_licenciatura.pdf $>$. Acesso em: 12 ago. 2012.

TEIXEIRA, B. R.; CYRINO, M. C. C. T. A comunicação escrita na formação inicial de professores de Matemática: potencialidades formativas da elaboração do Relatório de Estágio Supervisionado. Acta Scientiae (ULBRA), Canoas, Rio Grande do Sul, v. 12, n.1, p. 43-66, 2010.

. A elaboração do Relatório de Estágio Supervisionado e o desenvolvimento profissional na formação inicial de professores de Matemática. Boletim GEPEM, Rio de Janeiro, v. 58, n. 1, p. 71-88, 2011. 